\title{
PENGELUARAN KAYU DENGAN SISTEM KABEL LAYANG P3HH24 DI HUTAN TANAMAN KPH SUKABUMI
}

\author{
(Log Extraction Using P3HH24 Skyline System \\ in Plantation Forest of Sukabumi Forest District)
}

Oleh/By :

Sukadaryati \& Dulsalam ${ }^{1)}$

\begin{abstract}
Log extraction in plantation forest with relative smaller log dimension needs specific attention. The Centre for Forest Products Research and Development had engeneered $\mathrm{P} 3 \mathrm{HH} 24$ skyline system designed for log extraction from that specific forest condition. The research objective was to obtain technical and financial information of using $\mathrm{P} 3 \mathrm{HH} 24$ skyline system for log extraction in billy plantation forest. The results showed that volume of wood and working time ranged from 0.012 to $0.144 \mathrm{~m} 3$ with an average of $0.046 \mathrm{~m}^{3}$ and from 77.0 to 215.8 second/ turn with an average of 161.0 second/ turn, respectively. The productivity varied from 1.665 to $8.018 \mathrm{~m}^{3} /$ hour with an average of $3.562 \mathrm{~m}^{3} /$ hour while the average cost was $\mathrm{R} p$ 16,300/ $\mathrm{m}^{3}$. Log extraction using $\mathrm{P} 3 \mathrm{HH} 24$ skyline system was economicaly feasible with pay back periode $=1.39$ year; $N P V=R p 75,175.045 ; \mathrm{IRR}=66.4 \%$; and $B / C$ ratio $=1.51$.
\end{abstract}

Keywords: Plantation forest, $\mathrm{P} 3 \mathrm{HH} 24$ skyline system, log extraction, productivity, cost

\begin{abstract}
ABSTRAK
Pengeluaran kayu di areal hutan tanaman yang berbukit-bukit dengan ukuran kayu relatif lebih kecil perlu mendapat perhatian khusus. Pusat Penelitian dan Pengembangan Hasil Hutan telah membuat alat pengeluaran kayu dengan sistem kabel layang P3HH24 yang dirancang untuk mengeluarkan kayu pada areal berbukit. Tujuannya adalah untuk mendapatkan informasi teknis dan finansial penggunaan alat pengeluaran kayu tersebut. Hasil penelitian menunjukkan bahwa volume kayu yang dikeluarkan dan waktu kerja yang diperlukan berturut-turut berkisar dari 0,012-0,144 $\mathrm{m}^{3}$ (rata-rata $0,046 \mathrm{~m}^{3}$ ) dan 77,0 - 215,8 detik/rit (rata-rata 161,0 detik/rit). Produktivitas pengeluaran kayu bervariasi antara 1,665-8,018 $\mathrm{m}^{3} / \mathrm{jam}$ (rata-rata 3,562 $\mathrm{m}^{3} / \mathrm{jam}$ ), dan biaya pengeluaran kayu adalah Rp $16.300 / \mathrm{m}^{3}$. Pengeluaran kayu dengan sistem kabel layang $\mathrm{P} 3 \mathrm{HH} 24$ adalah layak secara ekonomi dengan Pay Back Periode $=1,39$ tahun; NPV $=$ Rp 75.175.045; $\mathrm{IRR}=66,4 \%$; dan B $/$ C Ratio $=1,51$.
\end{abstract}

Kata kunci: Hutan tanaman, sistem kabel layang P3HH24, pengeluaran kayu, produktivitas, biaya

\footnotetext{
1) Peneliti pada Pusat Penelitian dan Pengembangan Hasil Hutan, Bogor
} 


\section{PENDAHULUAN}

Pengeluaran kayu secara mekanis dengan menggunakan alat-alat berat seperti traktor penyarad di hutan tanaman yang berada pada topografi bergelombang atau berbukit-bukit dirasa kurang efektif. Hal ini disebabkan biaya investasi alat dan biaya pengoperasiannya lebih tinggi dibanding out put yang dihasilkan (dimensi kayu yang lebih kecil dibanding hutan alam). Di sisi lain, bila kayu dikeluarkan dengan tenaga manusia (secara manual) dirasa kurang manusiawi karena seperti memaksakan tenaga manusia yang terbatas kemampuannya. Padahal kurang lebih 30\% wilayah hutan tanaman di pulau Jawa berada pada kondisi areal yang demikian. Oleh karena itu perlu dicari alat pengeluaran kayu yang secara teknis memungkinkan dioperasikan pada areal tersebut dan layak secara ekonomis.

Salah satu alat yang dapat digunakan untuk mengeluarkan kayu pada areal yang bergelombang $\left(20-30^{\circ}\right)$ adalah alat yang dijalankan dengan sistem kabel layang. Dalam pengoperasiannya, kayu yang dikeluarkan dengan sistem kabel layang tidak menyentuh tanah (melayang) sehingga dapat melewati daerah-daerah yang berbatu, tanah rawa, atau berlumpur. Kondisi ini menguntungkan karena penurunan kualitas kayu akibat kayu rusak atau cacat dapat dihindari. Namun demikian sistem kabel layang mempunyai kekurangan karena jarak pengeluaran kayu sangat dibatasi oleh panjang kabel yang digunakan.

Alat pengeluaran kayu dengan sistem kabel layang sudah ada di pasaran dan sudah digunakan di beberapa perusahaan kayu. Yarder Thunder Bird TTY 70 digunakan untuk mengeluarkan kayu di PT Sumalindo Lestari Jaya (Kalimantan Timur) dengan produktivitas $12,4 \mathrm{~m}^{3} /$ jam dan biaya yang dikeluarkan Rp $39.000 / \mathrm{m}^{3}$ (Basari et al., 1999). Perhutani Unit III Jawa Barat menggunakan Yarder Iwafuji untuk mengeluarkan kayu tusam dengan produktivitas rata-rata 33,33 $\mathrm{m}^{3} \cdot \mathrm{hm} / \mathrm{jam}$ dan biaya operasional $\mathrm{Rp} 16.879,3 / \mathrm{m}^{3}$ (Basari, 2002). Alat pengeluaran kayu dengan sistem kabel layang tersebut dirancang agar produktivitas yang dihasilkannya tinggi karena daya/kekuatan mesin yang digunakan juga besar, yaitu antara 115 - 430 HP. Hal ini menyebabkan biaya investasi alat yang lebih tinggi dan juga biaya pengoperasian serta perawatannya. Belum lagi suku cadang alat kadang jarang ditemukan di pasaran. Kondisi ini semakin mempersulit perusahaan kayu terlebih pada masa krisis moneter sekarang ini.

Pusat Penelitian dan Pengembangan Hasil Hutan telah merekayasa alat pengeluaran kayu sistem kabel layang dengan biaya investasi lebih murah dan suku cadang mudah diperoleh di pasaran. Alat ini dirancang mampu mengeluarkan kayu hingga $0,5 \mathrm{~m}^{3} /$ rit, sehingga secara ekonomis layak diusahakan. Alat P3HH2O sistem kabel layang telah dicoba untuk mengeluarkan kayu di hutan tanaman di Pulau Laut (Kalimantan Selatan) dengan produktivitas rata-rata $1,980 \mathrm{~m}^{3} / \mathrm{jam}$ dan biaya yang dikeluarkan sebesar Rp $24.963 / \mathrm{m}^{3}$ (Dulsalam dan Tinambunan, 2002). Secara teknis alat ini memungkinkan untuk dioperasikan tetapi secara ekonomis belum layak, sehingga dilakukan penyempurnaan alat untuk meningkatkan produktivitasnya, yaitu dengan meningkatkan kekuatan mesin penggerak dari $20 \mathrm{HP}$ menjadi $24 \mathrm{HP}$ serta menambah panjang kabel menjadi $500 \mathrm{~m}$. Alat ini dikenal dengan nama alat kabel layang P3HH24. Untuk pertama kalinya, alat tersebut diuji coba di KPH Pekalongan Barat dengan produktivitas pengeluaran kayu rata-rata 2,519 $\mathrm{m}^{3} / \mathrm{jam}$, sedang rata-rata biayanya sebesar Rp 15.724/ $\mathrm{m}^{3}$ (Dulsalam dan Tinambunan, 2006).

Tulisan ini menyajikan hasil penelitian pengeluaran kayu menggunakan alat kabel layang P3HH24 di hutan tanaman dengan areal bergelombang atau berbukit-bukit. Tujuan dari 
penelitian ini adalah untuk mendapatkan informasi teknis dan finansial penggunaan alat kabel layang $\mathrm{P} 3 \mathrm{HH} 24$ di hutan tanaman dengan kondisi areal bergelombang atau berbukit-bukit.

\section{METODE PENELITIAN}

\section{A. Lokasi dan Waktu Penelitian}

Penelitian pengeluaran kayu dengan sistem kabel P3HH24 dilakukan di Bagian Kesatuan Pemangkuan Hutan (BKPH) Bojonglopang, Kesatuan Pemangkuan Hutan (KPH) Sukabumi, yang termasuk dalam wilayah Perum Perhutani Unit III Jawa Barat. Penelitian dilaksanakan pada bulan Agustus 2003.

\section{B. Bahan dan alat Penelitian}

Bahan yang digunakan dalam penelitian ini adalah sakel $(10 \mathrm{~cm}$ dan $12 \mathrm{~cm})$, penjepit kabel ( $8 \mathrm{~mm}$; $12 \mathrm{~mm}$; dan $14 \mathrm{~mm}$ ), kabel baja ( $10 \mathrm{~mm} ; 14 \mathrm{~mm}$; dan $18 \mathrm{~mm}$ ), dan katrol (5 ton dan 2 ton). Alat yang digunakan adalah meteran, alat pengukur waktu (stopwatch), alat tulis, tirfor, dan alat kabel layang P3HH24 (alat ini mempunyai kekuatan mesin 24 HP dan panjang kabel $500 \mathrm{~m})$.

\section{Prosedur Penelitian}

Prosedur kerja penelitian di lapangan terdiri dari beberapa tahap, yaitu tahap persiapan, tahap pemasangan alat, tahap pengoperasian dan tahan pembongkaran. Masing-masing tahap dijelaskan berikut ini.

1. Tahap persiapan
a. Menempatkan unit penggerak (yarder) pada tempat pengumpulan sementara yang telah ditentukan menurut rencana;
b. Mengatur posisi yarder sesuai dengan arah jalur pengeluaran kayu yang telah ditentukan dan diatur sedemikian rupa sehingga tingkat kenyamanan dan keselamatan terjamin;
c. Memasang kait/penguat pada unit yarder agar kedudukannya tidak berubah-ubah/ yang mantap.

2. Tahap pemasangan alat, yaitu kabel penguat (guyline) dan katrol yang dilakukan sebagai berikut:
a. Menentukan terlebih dahulu pohon sebagai tiang utama dan tiang pembantu;
b. Memanjat tiang utama dan tiang pembantu untuk menempatkan kabel penguat dan katrol;
c. Memasang katrol masing-masing di tiang utama dan tiang pembantu pada ketinggian tertentu sesuai yang dibutuhkan;
d. Memasang kabel penguat pada sebelah kiri dan kanan tiang utama;
e. Memasang kabel layang dan kabel tanpa ujung. Pemasangan kabel layang bertujuan untuk menyiapkan kabel layang dalam kegiatan pengeluaran kayu dan tuntuk pemasangan kereta pada kabel layang.


3. Tahap pengoperasian alat sistem kabel layang $\mathrm{P} 3 \mathrm{HH} 24$.

Pengoperasian alat dimulai dengan terlebih dahulu memanaskan mesin penggerak (yarder) dan memeriksa ulang seluruh pekerjaan pemasangan kabel, kereta, ataupun katrolkatrol. Dalam pengoperasiannya diperlukan 5 - 9 orang tenaga kerja, yaitu satu orang sebagai operator mesin, 2 - 4 orang menyiapkan dan mengait kayu yang akan dikeluarkan, satu orang memberi tanda (aba-aba), 1 - 3 orang melepas kaitan kayu dan mengumpulkan kayu di tempat pengumpulan kayu sementara. Jumlah tenaga kerja yang diperlukan bisa bervariasi tergantung kondisi lapangan dan keadaan hutan. Semua tenaga kerja harus dilengkapi helm pengaman untuk menjamin keselamatan kerja. Pengoperasian alat dimulai dengan meluncurkan kereta ke lokasi kayu yang akan dikeluarkan. Setelah kereta sampai di lokasi tersebut, pemberi tanda segera memberi aba-aba untuk menghentikan kereta dan mengendurkan kabel utama. Kayu yang sudah disiapkan segera dikaitkan pada katrol kemudian ditarik sehingga menempel kereta. Kereta yang sudah bermuatan tersebut kemudian ditarik lewat kabel utama menuju lokasi pengumpulan kayu sementara. Begitu kayu telah sampai di tempat tersebut, kabel tanpa ujung direm dan kabel utama dikendurkan sedemikian rupa sehingga muatan turun. Setelah muatan sampai di atas tanah, muatan dibongkar dan dikumpulkan di tempat pengumpulan sementara. Demikian seterusnya, setelah kereta kosong (tanpa muatan) segera diluncurkan menuju kayu yang akan dikeluarkan.

Perlu diperhatikan bahwa pada saat akan memulai pengoperasian alat, semua komponen harus diperiksa ulang, seperti kabel-kabel sesuai tempatnya, katrol harus sering diberi pelumas, kekencangan kabel utama tetap konstan, dll. Semuanya ini untuk memperlancar pekerjaan pengeluaran kayu dan menjamin keselamatan pekerja.

\section{Tahap pembongkaran alat}

Setelah kegiatan pengeluaran kayu selesai maka dilakukan pembongkaran alat. Pembongkaran alat dibedakan menjadi dua kegiatan, yaitu pembongkaran pada unit yarder dan pembongkaran pada tiang utama dan tiang pembantu.

Kegiatan pertama pada pembongkaran alat adalah mengendorkan kabel layang. Setelah itu, kabel utama, kabel tanpa ujung dan kereta dilepas. Kemudian menggulung kabel utama dengan mesin, sedang kabel tanpa ujung digulung secara manual. Pembongkaran pada tiang utama dan tiang pembantu adalah kegiatan pembongkaran katrol-katrol dan kabel penguat pada tiang utama dan tiang pembantu beserta perlengkapan pengikatnya. Semua peralatan yang telah dilepas dikumpulkan di tempat unit yarder yang selanjutnya siap untuk dipindahkan atau diangkut ke tempat lain. Pembongkaran ini memerlukan waktu antara 3 - 4 jam.

\section{Pengolahan Data}

Rumus-rumus yang digunakan dalam pengolahan data adalah sebagai berikut:

1. Produktivitas alat dihitung dengan rumus :

$$
\mathrm{P}=\frac{\mathrm{V}}{\mathrm{W}} \times 3600
$$


di mana: $\mathrm{P}=$ Produktivitas alat atau ekstraksi $\left(\mathrm{m}^{3} / \mathrm{jam}\right) ; \mathrm{V}=$ volume kayu yang dikeluarkan $\left(\mathrm{m}^{3}\right), \mathrm{W}=$ Waktu pengeluaran kayu (detik); $3600=$ konversi detik ke jam.

2. Volume kayu yang dikeluarkan dihitung dengan rumus sebagai berikut :

$$
\mathrm{V}=1 / 4 \pi \mathrm{D}^{2} \times \mathrm{L}
$$

di mana : V = Volume kayu $\left(\mathrm{m}^{3}\right) ; \mathrm{D}=$ Diameter rata-rata (pangkal dan ujung) kayu (m); $\mathrm{L}=$ Panjang kayu (m).

Biaya yang dihitung dibedakan menjadi biaya tetap dan biaya tidak tetap. Biaya tetap adalah biaya penghapusan, biaya asuransi, bunga dan pajak, sedang biaya tidak tetap meliputi biaya bahan bakar, pelumas, perawatan dan perbaikan, suku cadang dan tenaga kerja. Perhitungan biaya adalah sebagai berikut:

1. Biaya penyusutan (Wackerman, 1949):

$$
\mathrm{D}=\frac{\mathrm{M} \mathrm{R}}{\mathrm{Nt}}
$$

di mana : $\mathrm{D}=$ Penyusutan alat $(\mathrm{Rp} / \mathrm{jam}) ; \mathrm{M}=$ Investasi alat $(\mathrm{Rp}) ; \mathrm{R}=$ Nilai bekas alat $(\mathrm{Rp})$; $\mathrm{N}=$ Waktu ekonomis alat (tahun); $\mathrm{t}=$ Waktu operasi alat (jam/tahun).

2. Biaya bunga modal, pajak, asuransi, perawatan alat, bahan bakar, oli dan pelumas $(\mathrm{FAO}, 1992)$ :

a. Bunga modal $=\frac{\operatorname{Harga} \text { alat }(\mathrm{Rp}) \times 0,6}{\text { Umur pakai alat per tahun (jam) }} \times 0,18$

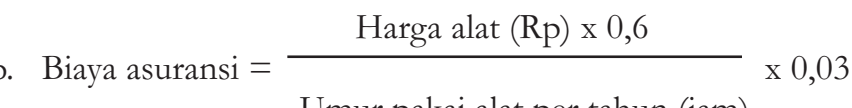

Umur pakai alat per tahun (jam)

c. Biaya pajak $=\frac{\text { Harga alat }(\mathrm{Rp}) \times 0,6}{\text { Umur pakai alat per tahun (jam) }} \times 0,02$

d. Biaya perawatan alat $=$ biaya penyusutan

e. Biaya bahan bakar = Penggunaan bahan bakar (liter/jam x harga bahan bakar per liter(Rp/liter))

f. Biaya oli dan pelumas $=0,1 \mathrm{x}$ biaya bahan bakar 
3. Upah dihitung dengan rumus :

$$
\mathrm{U}=\mathrm{T} / \mathrm{J} \text { x faktor sosial }
$$

di mana: $U=\operatorname{Upah}(\mathrm{Rp} / \mathrm{jam}) ; \mathrm{T}=$ Tarif upah $\left(\mathrm{Rp} / \mathrm{m}^{3}\right) ; \mathrm{J}=$ jam kerja per hari.

Kelayakan ekonomi ditentukan dengan metode periode penerimaan kembali (Pay Back Period), nilai bersih sekarang (Net Present Value, NPV), nilai penerimaan sekarang (Internal Rate of Return, IRR) dan rasio keuntungan dan biaya (Benefit Cost Ratio, B/C ratio).

\section{HASIL DAN PEMBAHASAN}

\section{A. Persiapan Pengeluaran Kayu}

Persiapan pengeluaran kayu meliputi kegiatan orientasi yang bertujuan untuk menentukan letak jalur kabel yang paling sesuai ditinjau dari aspek teknis dan lingkungan. Hal yang perlu diperhatikan dalam penempatan jalur kabel adalah dapat menjangkau potensi kayu yang sebesar-besarnya. Topografi lapangan bergelombang (berbukit) antara 15 - 25\%. Kayu yang dikeluarkan dari jenis mahoni dan pinus dengan umur tanam 16 - 29 tahun.

Berdasar pengukuran di lapangan, kelerengan lahan yang dilalui jalur kabel dibagi dalam tujuh seksi kelerengan, yaitu $-25,+45,-15,-3,+2,+38$ dan $+40 \%$. Tanda (-) yang mengikuti angka seksi kelerengan tersebut menunjukkan arah turun sedang tanda $(+)$ menunjukkan keadaan lapangan datar atau naik. Panjang seksi pada masing-masing kelerengan berturutturut sebesar 15,50 m; 4,30 m;13,80 m, 28,10 m;13,00 m; 37, 40 m dan 44,80 m. Jarak bentang kabel yang dipasang pada penelitian ini sepanjang 140,72 m dengan jarak datar 136,5 m. Tinggi tiang utama dan tiang pembantu masing-masing 4,15 $\mathrm{m}$ dan 1,35 $\mathrm{m}$. Kemiringan kabel utama sebesar 15\%. Dengan kemiringan sebesar 15\% tersebut pengeluaran kayu dengan sistem kabel layang dapat berjalan efektif. Pada Gambar 1 disajikan sketsa jalur kabel di lokasi penelitian.

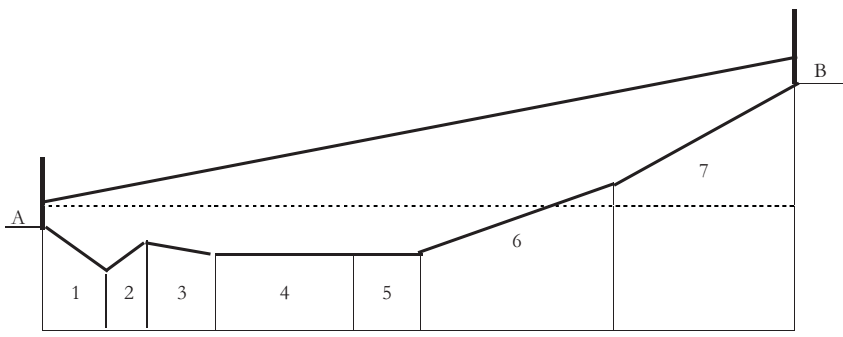

Gambar 1. Sketsa jalur kabel

Figure 1. Sketch of cable way

Keterangan (Remarks): A = Tiang utama (Head tree), $\mathrm{B}=$ Tiang pembantu (Tail tree)

\begin{tabular}{ccc|ccc|ccc} 
No & $\begin{array}{c}\text { Panjang lereng } \\
\text { (Slope length), } \mathrm{m}\end{array}$ & $\begin{array}{c}\text { Lereng } \\
\text { (Slope), } \%\end{array}$ & No & $\begin{array}{c}\text { Panjang lereng } \\
\text { (Slope length), } \mathrm{m}\end{array}$ & $\begin{array}{c}\text { Lereng } \\
\text { (Slope), } \%\end{array}$ & No & $\begin{array}{c}\text { Panjang lereng } \\
\text { (Slope length), } \mathrm{m}\end{array}$ & $\begin{array}{c}\text { Lereng } \\
\text { (Slope), \% }\end{array}$ \\
1 & 15,50 & -25 & 4 & 28,10 & -3 & 6 & 37,40 & +38 \\
2 & 4,30 & +45 & 5 & 13,00 & +3 & 7 & 44,80 & +40 \\
3 & 13,8 & -15 & & & & & &
\end{tabular}




\section{B. Produktivitas Pengeluaran Kayu}

Hasil percobaan pengeluaran kayu menggunakan alat kabel layang P3HH24 berupa diameter, panjang dan volume kayu yang dikeluarkan, jumlah batang per rit, waktu efektif dan produktivitas pengeluaran kayu disajikan pada Tabel 1.

Tabel 1. Hasil percobaan pengeluaran kayu dengan sistem kabel layang $\mathrm{P} 3 \mathrm{HH} 24$ Table 1. Result of log extraction using $\mathrm{P} 3 \mathrm{HH} 24$ skyline system

\begin{tabular}{|c|c|c|c|c|c|c|}
\hline No. & $\begin{array}{l}\text { Perihal } \\
\text { (Items) }\end{array}$ & $\begin{array}{l}\text { Satuan } \\
\text { (Unit) }\end{array}$ & $\begin{array}{c}\text { Kisaran } \\
\text { (Range) }\end{array}$ & $\begin{array}{l}\text { Rata-rata } \\
\text { (Average) }\end{array}$ & SD & $\begin{array}{r}C V \\
\%\end{array}$ \\
\hline 1. & $\begin{array}{l}\text { Diameter kayu } \\
\text { (Log diameter) }\end{array}$ & $\mathrm{cm}$ & $12,00-38,75$ & 20,84 & 7,37 & 18,8 \\
\hline 2. & $\begin{array}{l}\text { Panjang kayu } \\
\text { (Wood length) }\end{array}$ & $\mathrm{cm}$ & $101-130$ & 121,54 & 7,26 & 10,8 \\
\hline 3. & $\begin{array}{l}\text { Volume kayu } \\
\text { (Wood volume) }\end{array}$ & $\mathrm{m}^{3}$ & $0,096-0,224$ & 0,150 & 0,04 & 25,7 \\
\hline 4. & $\begin{array}{l}\text { Jumlah batang } \\
\text { (The number of } \log \text { ) }\end{array}$ & $\begin{array}{l}\text { batang/rit } \\
(\log / \text { turn })\end{array}$ & $1-6$ & 3,23 & 1,65 & 51,2 \\
\hline 5. & $\begin{array}{l}\text { Waktu kerja } \\
\text { (Working time) }\end{array}$ & $\begin{array}{c}\mathrm{detik} / \mathrm{rit} \\
\text { (second/turn) }\end{array}$ & $77,0-215,8$ & 160,99 & 29,98 & 18,6 \\
\hline 6. & $\begin{array}{l}\text { Produktivitas } \\
\text { (Productivity) }\end{array}$ & $\begin{array}{l}\mathrm{m}^{3} / \text { jam } \\
\left(m^{3} / \text { hour }\right)\end{array}$ & $1,665-8,018$ & 3,562 & 1,47 & 41,2 \\
\hline
\end{tabular}

Keterangan (Remarks) : SD = Simpangan baku (Standard Deviation); CV = Koefisien Keragaman (Coefficient of variation); Jumlah pengamatan (Number observed) $=30$.

Pada Tabel 1 dapat dilihat bahwa diameter kayu yang dikeluarkan dengan sistem kabel P3HH24 bervariasi antara 12,00 - 38,75 cm dengan rata-rata 20,8 cm. Panjang kayu yang dikeluarkan bervariasi antara $101-130 \mathrm{~cm}$ dengan rata-rata 121,54 cm. Jumlah kayu yang dikeluarkan per rit berkisar antara 1 - 6 batang/rit dengan rata-rata 3 batang/rit. Volume kayu yang dikeluarkan per ritnya tergantung diameter kayu, panjang kayu dan jumlah kayu yang dikeluarkan. Volume kayu yang dikeluarkan per rit bervariasi antara 0,096-0,224 $\mathrm{m}^{3}$ dengan rata-rata $0,150 \mathrm{~m}^{3} /$ rit.

Waktu kerja keseluruhan yang digunakan untuk mengeluarkan kayu berkisar antar 77,0 215,8 detik/rit dengan rata-rata 161,0 detik/rit. Waktu keseluruhan ini diukur mulai kegiatan kereta mendatangi kayu (muatan) dalam keadaan kosong, memuat, menarik, dan membongkar kayu di TPn. Operator yang terampil dan berpengalaman sangat dibutuhkan agar waktu yang ada dapat digunakan lebih efisien.

Ada beberapa kendala yang biasanya dijumpai dalam kegiatan pengeluaran kayu dengan sistem kabel layang, yaitu kabel yang membelit, rantai pengait lepas, katrol macet atau kayu yang akan dikeluarkan lepas dari kaitannya. Kendala ini dapat mempengaruhi waktu efektif yang diperlukan untuk mengeluarkan kayu. Untuk menghindari hal ini perlu dilakukan pemeriksaan ulang alat-alat yang akan dioperasikan. 
Produktivitas alat $\mathrm{P} 3 \mathrm{HH} 24$ untuk mengeluarkan kayu dalam penelitian ini bervariasi antara 1,665 - 8,018 $\mathrm{m}^{3} /$ jam dengan rata-rata 3,562 $\mathrm{m}^{3} / \mathrm{jam}$. Produktivitas ini tergantung kepada volume kayu yang dikeluarkan dan waktu yang diperlukan untuk mengeluarkan kayu. Produktivitas dapat ditingkatkan dengan memperbesar volume kayu yang dikeluarkan per ritnya, namun langkah ini dibatasi oleh kemampuan mesin yang dipakai. Kalau demikian, langkah lain yang dapat ditempuh untuk meningkatkan produktivitas adalah dengan mengefisienkan waktu pengeluaran kayu, yaitu dengan memperkecil waktu yang tidak efektif, seperti waktu mendatangi muatan, memuat dan membongkar muatan.

Besar kecilnya produktivitas pengeluaran kayu ini pada akhirnya akan mempengaruhi biaya pengeluaran kayu. Hal ini bisa dipahami karena biaya pengeluaran kayu per $\mathrm{m}^{3}$ diperolah dengan membagi biaya pengeluaran kayu per jam ( $\mathrm{Rp} / \mathrm{jam})$ dengan produktivitasnya $\left(\mathrm{m}^{3} / \mathrm{jam}\right)$. Produktivitas yang tinggi dapat menurunkan biaya pengeluaran kayu per $\mathrm{m}^{3}$ - nya. Dengan kata lain, biaya pengeluaran kayu dapat ditekan bila produktivitas pengeluaran kayu ditingkatkan.

\section{B. Biaya Pengeluaran Kayu}

Biaya pengeluaran kayu dengan sistem kabel layang dapat dihitung setelah produktivtias, biaya kepemilikan dan biaya pengoperasian alat diketahui terlebih dahulu. Dasar perhitungan pengeluaran kayu dengan sistem kabel layang dapat dilihat pada Tabel 2.

Tabel 2. Dasar perhitungan biaya pengeluaran kayu dengan sistem kabel layang Table 2. Calculation base of log extraction cost using skyline system

\begin{tabular}{|c|l|c|c|}
\hline No. & \multicolumn{1}{|c|}{ Uraian (Items) } & Satuan (Units) & Nilai (Price) \\
\hline 1. & Harga alat (Equipment price) & $\mathrm{Rp} /$ unit & 60.000 .000 \\
2. & Umur pakai alat (Equipment life time) & tahun (year) & 5 \\
3. & Jam kerja per tahun (Annual working hour) & jam/tahun (hour/year) & 2000 \\
4. & Harga solar (Diesel fuel price) & $\mathrm{Rp} /$ liter (Rp/litre) & 1.650 \\
5. & Upah operator (Operator's wage) & $\mathrm{Rp} /$ hari (Rp/ hour) & 150.000 \\
6. & Jam kerja per hari (Daily working hour) & jam/hari (hour/ day) & 8 \\
7. & Bunga bank (Inrterest rate) & $\%$ & 18 \\
8. & Asuransi (Insurance cost) & $\%$ & 3 \\
9. & Pajak (Tax cost) & $\%$ & 2 \\
10. & Biaya sosial (Social cost) & 43 \\
\hline
\end{tabular}

Berdasar Tabel 2, dengan menggunakan rumus (3) -(10), biaya pengeluaran kayu dengan sistem kabel layang dapat dihitung dengan hasil seperti tercantum pada Tabel 3. 
Tabel 3. Biaya pengeluaran kayu dengan sistem kabel layang Table 3. Log extraction cost using skyline system

\begin{tabular}{|c|l|c|}
\hline No. & \multicolumn{1}{|c|}{ Komponen biaya (Cost components) } & Rp/jam (Rp/hour) \\
\hline 1. & Biaya penyusutan (Depreciation cost) & 5.400 \\
2. & Biaya bunga modal (Capital interest cost) & 3.240 \\
3. & Biaya perawatan mesin (Maintenance cost) & 5.400 \\
4. & Biaya Asuransi (Insurance cost) & 540 \\
5. & Biaya pajak (Tax cost) & 360 \\
6. & Biaya bahan bakar (Fuel cost) & 3.300 \\
7. & Biaya oli/pelumas (Oil/grease cost) & 290 \\
8. & Biaya upah (Wage cost) & $26.812,5$ \\
\hline \multicolumn{2}{|r}{ Jumlah (Total) } & $45.342,5$ \\
\hline
\end{tabular}

Tabel 3 menunjukkan bahwa jumlah biaya pengeluaran kayu dengan sistem kabel layang P3HH24 per jam adalah sebesar Rp 45.342,4. Rata-rata produktivitas pengeluaran kayu

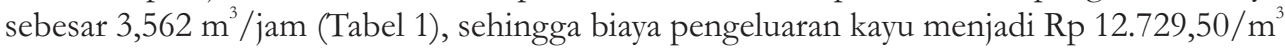
atau dibulatkan menjadi $\mathrm{Rp} 12.750 / \mathrm{m}^{3}$.

Biaya pengeluaran kayu tersebut belum termasuk biaya pemasangan dan pembongkaran alat. Dalam penelitian ini, jumlah tenaga kerja yang diperlukan 6 orang dan waktu yang digunakan untuk memasang dan membongkar alat adalah 20 jam yang terdiri dari waktu pemasangan alat selama 15 jam dan waktu pembongkaran alat selama 5 jam. Upah tenaga kerja untuk memasang dan membongkar alat sangat tergantung standar upah tenaga kerja setempat, jadi setiap daerah mempunyai standar upah yang berbeda-beda.

Upah tenaga kerja untuk pasang dan bongkar alat di BKPH Bojonglopang sebesar Rp 150.000/hari. Bila waktu kerja efektif 6 jam/hari, maka upah tenaga kerja per jam menjadi Rp 25.000/jam (Rp 150.000/hari : 6 jam/hari). Selain upah tenaga kerja setempat, biaya pemasangan dan pembongkaran alat juga tergantung dari potensi kayu yang dikeluarkan dari jalur kabel, sedang besarnya potensi kayu tergantung panjang jalur kabel yang dipakai. Potensi kayu pada jalur kabel adalah $140,720 \mathrm{~m}^{3}$ per ha.

Berdasar waktu pemasangan dan pembongkaran alat, potensi kayu yang dikeluarkan dan biaya upah tenaga kerja per jam, biaya pemasangan dan pembongkaran kayu per jam dapat dihitung sebagaiberikut:

Biaya pemasangan dan pembongkaran alat $=\frac{\mathrm{Rp} 25.000 / \mathrm{jam} \times 20 \mathrm{jam}}{140,720 \mathrm{~m}^{3}}=\mathrm{Rp} 3.553,20 / \mathrm{m}^{3}$

Dengan demikian rata-rata biaya pengeluaran kayu dengan sistem kabel layang per $\mathrm{m}^{3}$ sebesar $\mathrm{Rp}(12.729,50+3.553,20) / \mathrm{m}^{3}=\mathrm{Rp} 16.282,70 / \mathrm{m}^{3}$ atau dibulatkan menjadi $\operatorname{Rp} 16.300 / \mathrm{m}^{3}$. 
Penentuan kelayakan ekonomis dilakukan dengan membandingkan besarnya biaya pengeluaran kayu yang dikeluarkan menggunakan sistem kabel layang P3HH24 dengan biaya pengeluaran kayu secara manual. Upah pengeluaran kayu secara manual (dengan tenaga manusia) yang ditetapkan Perum Perhutani Unit III Jawa Barat dan diberlakukan di BKPH Bojonglopang pada waktu penelitian berlangsung sebesar Rp $25.000 / \mathrm{m}^{3}$. Dengan demikian dapat dikatakan secara sederhana bahwa biaya pengeluaran kayu dengan sistem kabel layang P3HH24 lebih ekonomis dibandingkan dengan sistem manual karena biaya yang dikeluarkannya lebih rendah, yaitu masing-masing sebesar Rp 16.300/ $\mathrm{m}^{3}$ (sistem kabel layang P3HH24) dan $\operatorname{Rp} 25.000 / \mathrm{m}^{3}$ (manual).

Untuk mengetahui tingkat kelayakan ekonomis dilakukan analisis finansial pengeluaran kayu dengan sistem kabel layang P3HH24. Hasil analisis finansial pengeluaran kayu dengan sistem kabel layang P3HH24 dapat dilihat pada Tabel 4.

Tabel 4. Analisis finansial pengeluaran kayu dengan sistem kabel layang $\mathrm{P} 3 \mathrm{HH} 24$ Table 4. Financial analysis of log extraction using $\mathrm{P} 3 \mathrm{HH} 24$ skyline system

\begin{tabular}{|c|c|c|c|}
\hline No. & Perihal (Items) & Satuan (Unit) & Jumlah (Total) \\
\hline 1. & $\begin{array}{l}\text { Jangka waktu pengembalian } \\
\text { (Pay Back Period) }\end{array}$ & tahun (year) & 1,39 \\
\hline 2 & $\begin{array}{l}\text { Nilai bersih sekarang } \\
\text { (Net Present Value (NPV) }\end{array}$ & Rupiah & 75.175 .045 \\
\hline 3. & $\begin{array}{l}\text { Nilai penerimaan } \\
\text { (Internal Rate of Return (IRR)) }\end{array}$ & $\%$ & 66,4 \\
\hline 4. & Rasio pendapatan/biaya (BC Ratio) & - & 1,51 \\
\hline
\end{tabular}

Berdasar Tabel 4 dapat dilihat bahwa pay back period yang diperoleh sebesar 1,39 tahun. Ini berarti periode waktu pengembalian modal adalah 1,39 tahun. Bila umur pakai alat 5 tahun (Tabel 2) sementara waktu pengembalian hanya 1,39 tahun ( $<5$ tahun), maka dapat dikatakan alat P3HH24 adalah layak diusahakan. Hasil perhitungan NPV diperoleh Rp 75.175.045, yang berarti bahwa dengan hasil Rp 75.175.045 selama 5 tahun umur pakai alat, dapat membeli alat baru sebanyak 1 (satu) unit seharga Rp 60.000.000/unit (Tabel 3) dan masih ada sisa Rp 15.175.040. Dengan kata lain, alat P3HH24 adalah layak karena besarnya NPV atau nilai bersih sekarang lebih besar dari nol. Nilai IRR atau nilai penerimaan sekarang yang diperoleh sebesar 66,4\%. Jika dibanding bunga bank sebesar 18\% (Tabel 4), maka IRR sebesar ini termasuk layak karena nilai IRR (66,4\%) lebih besar daripada bunga bank (18\%). Atau dapat dikatakan pula bahwa dengan bunga bank yang diberlakukan di atas $18 \%$ pun, asal masih di bawah 66,4\%, alat P3HH24 masih layak diusahakan. Nilai BC ratio atau rasio keuntungan adalah perbandingan antara besarnya keuntungan dengan biaya pengoperasian alat. Nilai yang diperoleh sebesar 1,51 ternyata lebih dari 1, berarti dapat dikatakan layak.

Berdasar hasil perhitungan Pay Back Periode, NPV, IRR dan BC Ratio, ternyata alat P3HH24 adalah layak untuk diusahakan. Dengan kata lain, alat P3HH24 yang digunakan untuk mengeluarkan kayu di BKPH Bojonglopang adalah layak secara ekonomis. Dapat dikatakan juga bahwa alat $\mathrm{P} 3 \mathrm{HH} 24$ secara teknis dan ekonomis adalah layak bila dioperasikan 
pada kondisi lapangan dan standar upah yang berlaku sama seperti di BKPH Bojonglopang. Namun demikian uji kelayakan ini tidak bisa diberlakukan secara umum, karena pada kondisi lapangan yang berbeda (topografi) sortimen kayu yang berbeda, misalnya, akan mempengaruhi produktivitas pengeluaran kayu yang dapat dihasilkan, sedang standar upah yang berbeda dapat mempengaruhi besarnya biaya pengeluaran kayu tersebut.

\section{B. Dampak Pengeluaran Kayu dengan Sistem Kabel Layang}

Pengeluaran kayu dengan sistem kabel layang menimbulkan gangguan lingkungan lebih kecil dibanding alat pengeluaran kayu dengan traktor. Kerusakan lantai hutan yang ditimbulkan akibat penggunaan sistem kabel layang lebih kecil daripada dengan traktor berban rantai baja. Kerusakan lantai hutan ini tergantung pada lebar alat sarad yang digunakan. Semakin lebar alat sarad, kerusakan lantai hutan yang ditimbulkan semakin besar, demikian sebaliknya. Lebar jalur kabel lebih kecil dibanding traktor berban rantai baja, yaitu masing-masing sebesar $2 \mathrm{~m}$ dan $4 \mathrm{~m}$, sehingga kerusakan lantai hutan yang ditimbulkan traktor berban rantai baja lebih besar daripada kabel layang. Selain itu titik tekan yang terjadi akibat penggunaan sistem kabel layang lebih rendah daripada traktor berban rantai baja. Ini berarti pemadatan tanah yang terjadi akibat sistem kabel layang lebih rendah daripada traktor berban rantai baja. Dengan demikian dalam persiapan lahan penanaman, lahan bekas jalan sarad traktor memerlukan pengolahan yang intensif.

Besar kecilnya persentase keterbukaan tanah akibat kegiatan pengeluaran kayu dapat didekati dengan pengukuran panjang dan lebar jalur kabel untuk sistem kabel layang dan kerapatan jalan untuk sistem traktor. Kerapatan jalan sarad adalah panjang jalan sarad (m) per satuan luas (ha). Semakin besar kerapatan jalan sarad maka semakin besar pula keterbukaan lahan yang terjadi, demikian sebaliknya. Sebagai gambaran, kerapatan jalan sarad hutan alam di semenanjung Malaysia berkisar antara $6283 \mathrm{~m}$ dengan rata-rata 72,5 m/ ha (Anonim, 1976). Sementara itu, kerapatan jalan sarad di areal HTI rata-rata dapat mencapai $100 \mathrm{~m} /$ ha. Jika panjang dan lebar jalur kabel diketahui masing-masing sebesar $150 \mathrm{~m}$ (panjang jalur kabel yang digunakan dalam penelitian ini) dan $2 \mathrm{~m}$, maka keterbukaan lahan yang ditimbulkan akibat penggunaan sistem kabel layang sebesar $2 \%$ atau $300 \mathrm{~m}^{2}$ per 1,5 ha (300 m x $\left.50 \mathrm{~m}\right)$. Sedang keterbukaan lahan yang ditimbulkan akibat penggunaan traktor berban rantai baja sebesar 4\% atau $400 \mathrm{~m}^{2}$ per ha. Dengan demikian keterbukaan lahan yang terjadi akibat penggunaan kabel layang lebih kecil daripada traktor berban rantai baja.

Kerusakan tanah lantai hutan berupa penggusuran/pengelupasan lapisan tanah dapat dikurangi bila kegiatan pengeluaran kayu dilakukan dengan "lifting", yaitu cara pengeluaran kayu di mana kayu yang disarad melayang di udara atau hanya sebagian yang menyentuh tanah. Dengan cara ini lebih menguntungkan karena cacat kayu yang terjadi akibat gesekan dengan tanah, terbentur batu atau tunggak juga dapat dihindari. Dengan demikian penurunan kualitas kayu akibat kegiatan pengeluaran kayu dapat diminimalkan. 


\section{KESIMPULAN DAN SARAN}

\section{Kesimpulan}

Dari hasil dan pembahasan tersebut dapat disimpulkan sebagai berikut :

1. Volume kayu yang dikeluarkan berkisar antara $0,096-0,224 \mathrm{~m}^{3} /$ rit dengan rata-rata 0,150 $\mathrm{m}^{3} /$ rit, sedang waktu kerja yang dipakai berkisar antara 77,0 - 215,8 detik/ rit dengan ratarata $161,0 \mathrm{detik} /$ rit.

2. Produktivitas pengeluaran kayu berkisar antara $1,665-8,018 \mathrm{~m}^{3} /$ jam dengan rata-rata $3,562 \mathrm{~m}^{3} /$ jam.

3. Biaya rata-rata pengeluaran kayu dengan alat sistem kabel layang P3HH24 sebesar $\operatorname{Rp} 16.300 / \mathrm{m}^{3}$.

4. Secara ekonomi alat kabel layang P3HH24 yang dipakai untuk mengeluarkan kayu di BKPH Bojonglopang adalah layak diusahakan dengan nilai Pay Back Periode, NPV, IRR, dan B/C ratio berturut-turut adalah sebesar 1,39 tahun; Rp 75.175.045; 66,4\%; dan 1,51.

5. Gangguan lingkungan yang ditimbulkan oleh penggunaan sistem kabel layang P3HH24 untuk mengeluarkan kayu lebih rendah daripada sistem traktor.

\section{Saran}

1. Perlu penyempurnaan sistem transmisi untuk meningkatkan produktivitas misalnya dengan sistem transmisi langsung yaitu dari kotak roda gigi (gear box) ke drum penggulung kabel utama dan kabel tanpa ujung.

2. Perlu dipersiapkan pengganti tiang utama manakala pohon yang dipakai sebagai tiang utama di lapangan tidak tersedia.

3. Perlu penyempurnaan tata letak mesin dan bagian pengoperasian pada unit yarder (mesin penggerak) agar lebih ergonomis.

\section{DAFTAR PUSTAKA}

Anonim. 1976. A study of the forest operations of Syarikat Jangka during the first year exploitation under sustainable yield management. Yunit Pengurusan Hutan. Forestry Department. Kuala Lumpur.

Binkley, V.W \& H.H. Lysons. 1968. Planning single span skyline. U.S. Department of Agriculture, Forest Service. Oregon.

Brown, N. C. 1949. Logging. The principle and method of harvesting timber in the United States and Canada. John Wiley and Sons Inc. New York.

Conway, S. 1978. Logging practice:Principles of timber harvesting system. Miller Freeman Publication Inc. San Fransisco.

Dulsalam, M.M. Idris \& W. Endom. 1997. Produktivitas dan biaya pengeluaran kayu dengan sistem kabel P3HH20. Buletin Penelitian Hasil Hutan 15 (3): 151-161. Pusat Penelitian dan Pengembangan Hasil Hutan. Bogor. 
Dulsalam dan D. Tinambunan. 2002. Uji coba pengeluaran kayu di hutan tanaman Pulau Laut dengan sistem kabel layang P3HH20 yang disempurnakan. Buletin Penelitian Hasil Hutan 20(4):313331. Pusat Penelitian dan Pengembangan Hasil Hutan. Bogor.

. 2006. Produktivitas dan biaya pengeluaran kayu dari hutan tanaman dengan sistem kabel layang P3HH24 di KPH Pekalongan Barat. Jurnal Penelitian Hasil Hutan 24(1):79-90. Pusat Penelitian dan Pengembangan Hasil Hutan. Bogor.

FAO. 1992. Cost control in forest harvesting and road construction. FAO Forestry Paper No. 99. Rome.

Wackerman, A.E. 1949. Harvesting timber crops. McGrow-Hill Book Company Inc. New York. 